\title{
PERFORMANCE EVALUATION OF LEAD RUBBER ISOLATORS UNDER SEISMIC LOADS
}

\author{
Shankarling S Mandewali ${ }^{1}$, H.Narendra ${ }^{2}$ \\ ${ }^{\text {I}}$ PG student, Department of Civil Engineering, M.S. Ramaiah Institute of Technology, Bangalore, Karnataka, India - \\ 560054 \\ ${ }^{2}$ Faculty in Civil Engineering, Department of Civil Engineering, M.S. Ramaiah Institute of Technology, Bangalore, \\ Karnataka, India -560054
}

\begin{abstract}
Earthquake is the natural phenomenon that occurs due to sudden movement of the earth surface, releasing tremendous amount of energy which proves to be a curse to the structural integrity and hence to the mankind. In order to safeguard the structural integrity, from the past few decades' ductility method has been adopted. Ductility method ensures the life safety but structural integrity is not ensured. Hence in order to enhance the structural safety, many structural control concepts have been developed in recent times. Base isolation, Seismic damper etc are some of the structural control concepts which are being used widely nowadays. Base isolation is a passive type of energy dissipation system in which the superstructure and substructure are decoupled by a rubber media known as isolators. The basic principle behind the base isolation system is to elongate the fundamental period of the structure; thereafter the seismic energy transmitted to the structure will be significantly reduced. Thus the superstructure acts as a rigid body and damages to the non-structural elements are also reduced. In the present study, a G+10 reinforced concrete structure is considered, $4 \times 4$ bays, $5 \mathrm{~m}$ in both directions. Non-linear time history analysis of the building is carried out by using SAP2000 computer package. Analysis is carried out for time history records of zone V (confirming to BIS) and El-Centro ( $N$-S component).
\end{abstract}

Keywords: Base isolation, Lead rubber bearing (LRB), Responses, Non-Linear time history, Fundamental period. -***

\section{INTRODUCTION}

Earthquake is a natural phenomenon in which sudden release of energy takes place due to movements of the tectonic plates. This sudden release in energy travels in the form of the waves through body and surface of earth, known as seismic waves. When these seismic waves hit the foundation of the building, these are transmitted to the superstructure causing violent shaking, leading to devastating effects such as damage or collapse of the entire structure. Hence the risk to human life, financial loss, social sufferings are immense.

In order to overcome these crisis, from the past decades ductility based earthquake resistant design of structure is opted. Ductility based method ensures life safety but does not ensures structural integrity, hence after a severe earthquake, the functionality of the structures becomes questionable which are of prime importance in buildings such as hospital, data storage structures etc. Hence in order to ensure the structural safety and functionality during and after the earthquake, many non-structural control concepts are adopted. Some of the non-structural control concept which is frequently used now-a-days is passive, semi-active, active and hybrid.

Base isolation is a passive type of control concept. The basic principle behind base isolation technique is that the superstructure and substructure are decoupled means of an a media known as isolators. By the introduction of isolators between superstructure and substructure, the fundamental period of the superstructure is elongated. Hence by elongating the fundamental period, the responses of the building such as acceleration, storey shear, and inter-storey drift can be reduced significantly. Due to elongation the fundamental period, the superstructure acts as rigid body, undergoing same displacement throughout.

In the present study, a $\mathrm{G}+10$ reinforced concrete structure is considered, 4 x 4 bays, $5 \mathrm{~m}$ in both directions. Non-linear time history analysis of the building is carried out by using SAP2000 computer package. Analysis is carried out for time history records of zone $\mathrm{V}$ (confirming to BIS) and El-Centro (N-S component).

\section{ANALYTICAL MODEL}

A G+10 RC structure, 4 bays in each direction with $5 \mathrm{~m}$ span is considered. The storey height of the building with 3 $\mathrm{m}$ with plinth height of $1.5 \mathrm{~m}$, hence the height of the building is $34.5 \mathrm{~m}$. The dimensions of the beam and column are $230 \times 450 \mathrm{~mm}$ and $600 \times 600 \mathrm{~mm}$ respectively. Material properties considered for the present study are M30 concrete and Fe415 steel. Slab thickness of $175 \mathrm{~mm}$ and wall thickness of $230 \mathrm{~mm}$ were considered. Live load and super dead of 4 and $1.5 \mathrm{kN} / \mathrm{m}^{2}$ respectively is applied. $\mathrm{P}-\Delta$ effect is considered to include geometric nonlinearity and modal damping of $5 \%$ is considered. Hard soil strata is used for the 


\section{DESIGN OF ISOLATORS}

Lead rubber bearing (LRB) are used in the present study as the isolating media. LRB consist of natural rubber with one or more lead core which acts as an energy dissipation media. LRB design is carried out confirming to UBC97. The properties of LRB which are used in the analysis are listed in table 1 .

Table 1: properties of LRB

\begin{tabular}{|l|l|l|}
\hline Required Stiffness Keff $=$ & 4728.57876 & $\mathrm{kN} / \mathrm{m}$ \\
\hline $\begin{array}{l}\text { Bearing Horizontal Stiffness } \\
\mathrm{Kb}=\end{array}$ & 2528.57537 & $\mathrm{kN} / \mathrm{m}$ \\
\hline Vertical Stiffness Kv $=$ & 3368632.04 & $\mathrm{kN} / \mathrm{m}$ \\
\hline Yield Force F $=$ & 184.57 & $\mathrm{kN}$ \\
\hline Stiffness Ratio $=$ & 0.1 & \\
\hline Damping $=$ & 0.05 & \\
\hline
\end{tabular}

\section{RESULTS AND DISCUSSION}

To find the effectiveness of base isolation, parameters such as displacement, inter-storey displacement, acceleration, axial load, base shear and energy dissipation are considered and are compared with fixed base building. The results for the above parameters considered are enlisted as below. Table 2 describes the displacements for both earthquake inputs.

Table 2: Displacement in $\mathrm{mm}$

\begin{tabular}{|l|l|l|l|l|}
\hline \multirow{2}{*}{ Points } & \multicolumn{3}{|l}{ Displacement } & \multicolumn{2}{l|}{ El-Centro } \\
\cline { 2 - 5 } & \multicolumn{2}{|l|}{ Zone V } & FB & BI \\
\cline { 2 - 5 } & FB & BI & 187.1 & 225.5 \\
\hline 12 & 242.5 & 208.1 & 182.5 & 222.9 \\
\hline 11 & 235.6 & 201.5 & 175.1 & 218.7 \\
\hline 10 & 224.2 & 196.7 & 164.7 & 212.5 \\
\hline 9 & 208.9 & 189.8 & 152 & 204.2 \\
\hline 8 & 192 & 180.7 & 152 & 193.8 \\
\hline 7 & 174.3 & 169.4 & 137.3 & 181.3 \\
\hline 6 & 156 & 163.1 & 120.4 & 166.9 \\
\hline 5 & 136 & 159.7 & 100.8 & 150.3 \\
\hline 4 & 108.9 & 151.6 & 78.32 & 131.7 \\
\hline 3 & 75.83 & 138.4 & 53.4 & 111.7 \\
\hline 2 & 39.42 & 121 & 27.4 & 93.24 \\
\hline 1 & 6.528 & 103.1 & 4.514 & \\
\hline 0 & 0 & & 0 & \\
\hline
\end{tabular}

The variation of the displacements of fixed and isolated buildings for zone $\mathrm{V}$ and El-Centro earthquake inputs are plotted in fig 1 and fig 2 respectively.

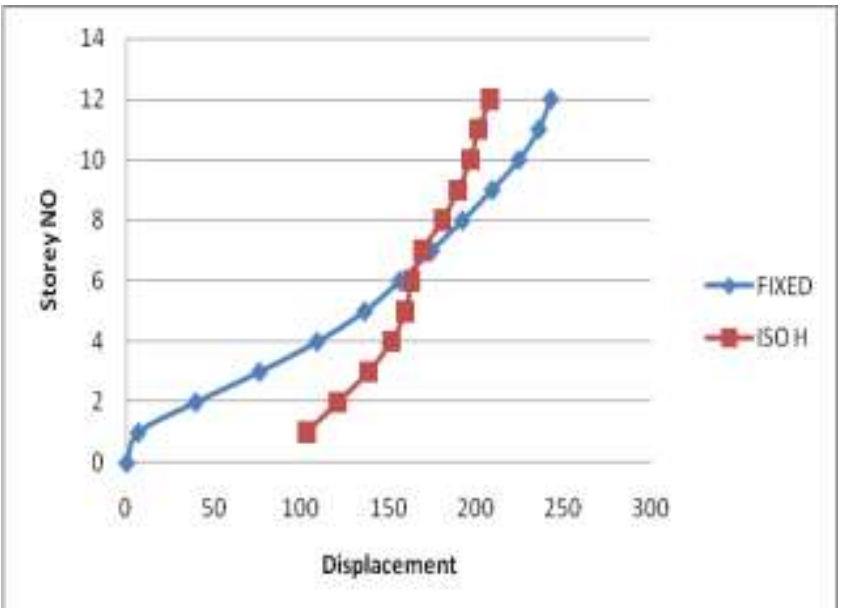

Fig 1: Variation of Displacement (Zone V)

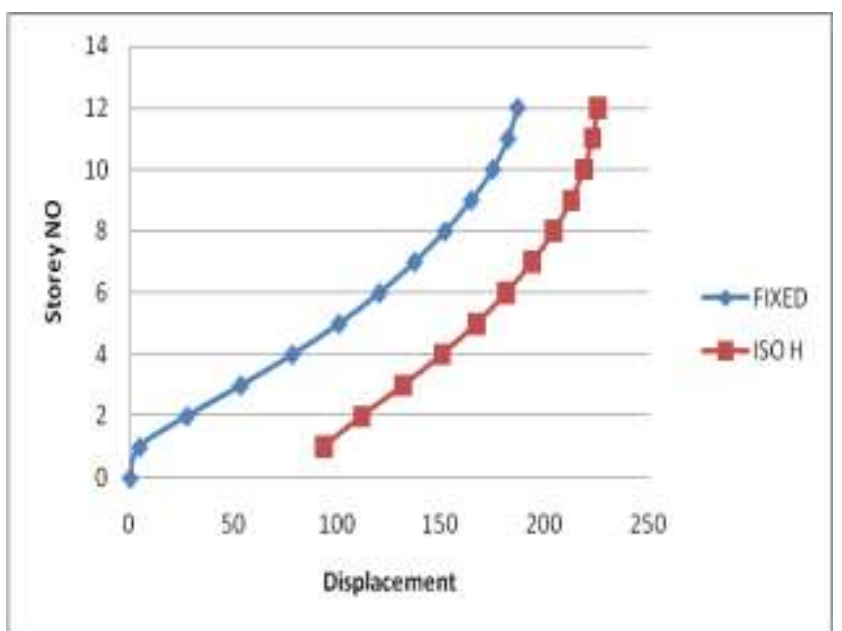

Fig 2: Variation of Displacement (El-Centro)

The variation of the inter-storey drift of fixed and isolated buildings for zone $\mathrm{V}$ and El-Centro earthquake inputs are plotted in fig 3 and fig 4 respectively.

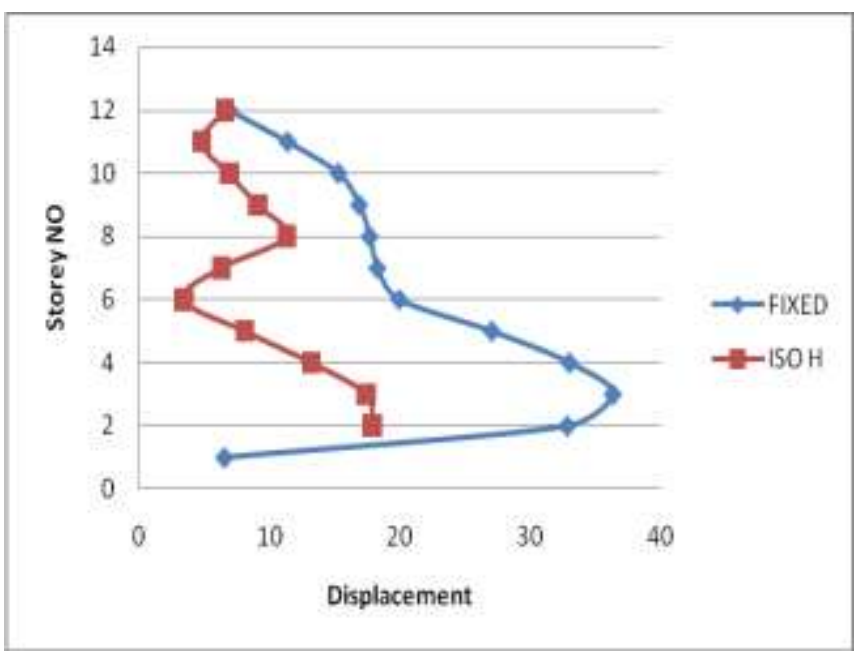

Fig 3: Variation of Inter-Storey Drift (Zone V) 


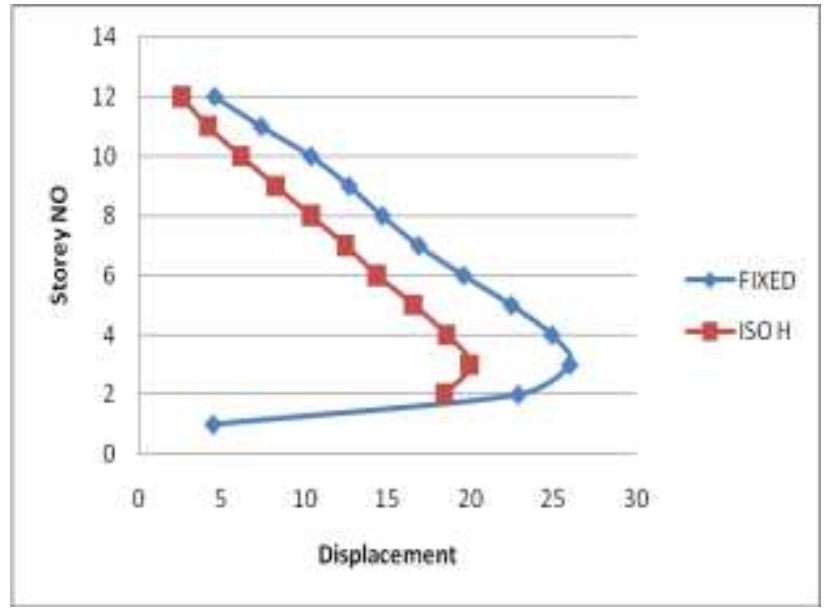

Fig 4: Variation of Inter-Storey Drift (El-Centro)

The variation of the acceleration of fixed and isolated buildings for zone $\mathrm{V}$ and El-Centro earthquake inputs are plotted in fig 5 and fig 6 respectively.

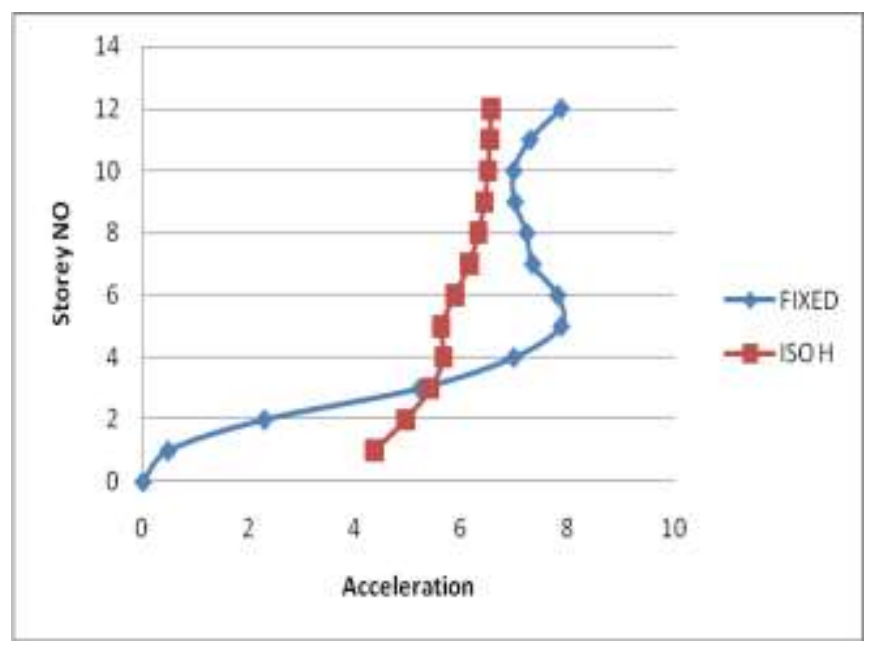

Fig 5: Variation of Acceleration (Zone V)

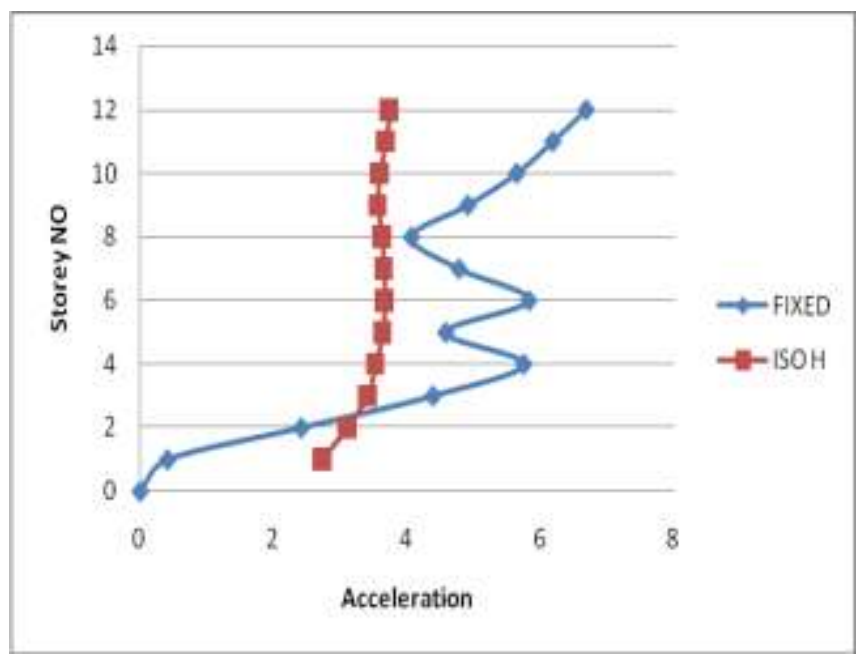

Fig 6: Variation of Acceleration (El-Centro)

The variation of the axial loads of fixed and isolated buildings for zone $\mathrm{V}$ and El-Centro earthquake inputs are plotted in fig 7 and fig 8 respectively.

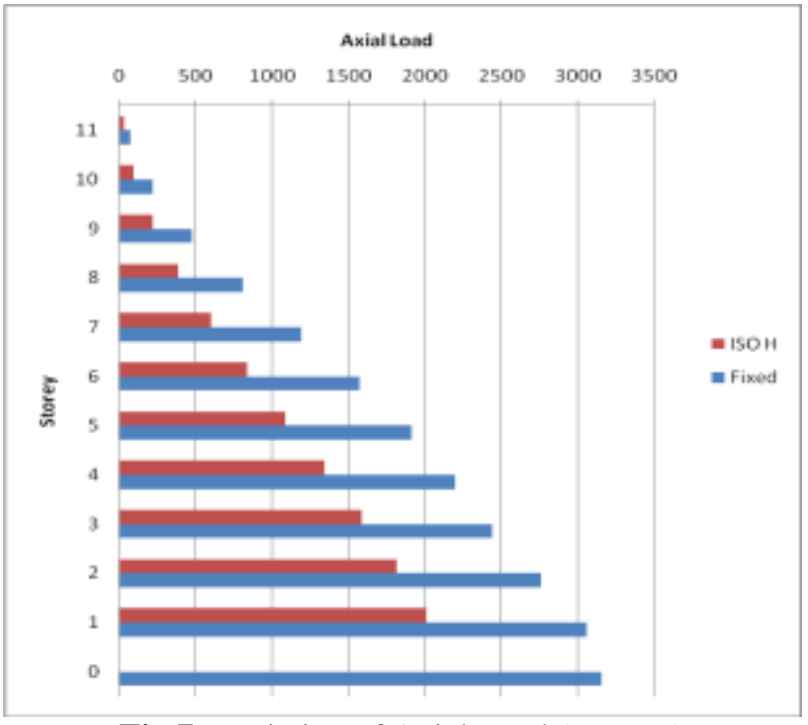

Fig 7: Variation of Axial Load (Zone V)

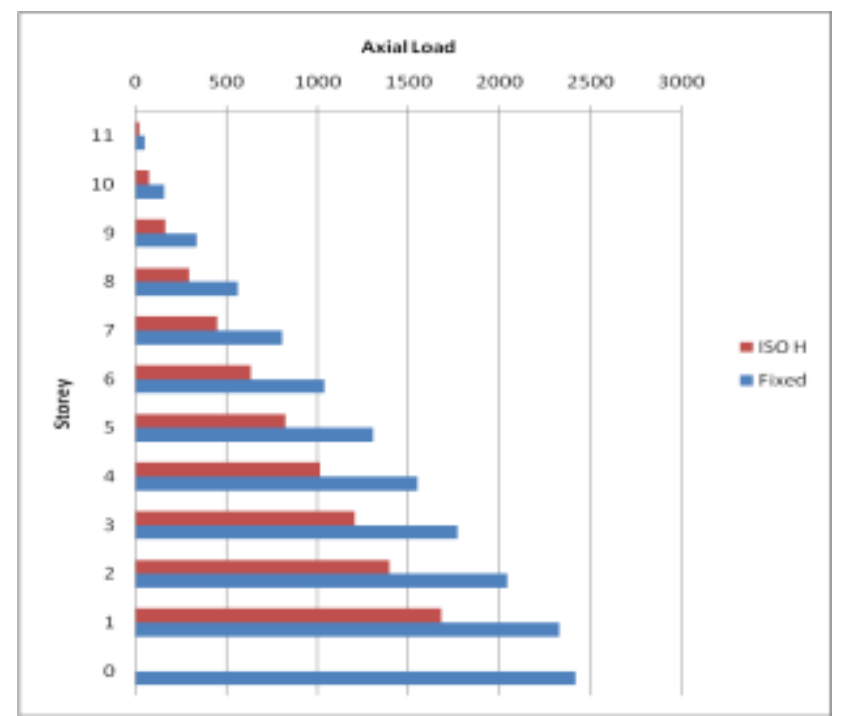

Fig 8: Variation of Axial Load (El-Centro)

The variation of the base shear of fixed and isolated buildings for zone $\mathrm{V}$ and El-Centro earthquake inputs are plotted in fig 9 and fig 10 respectively.

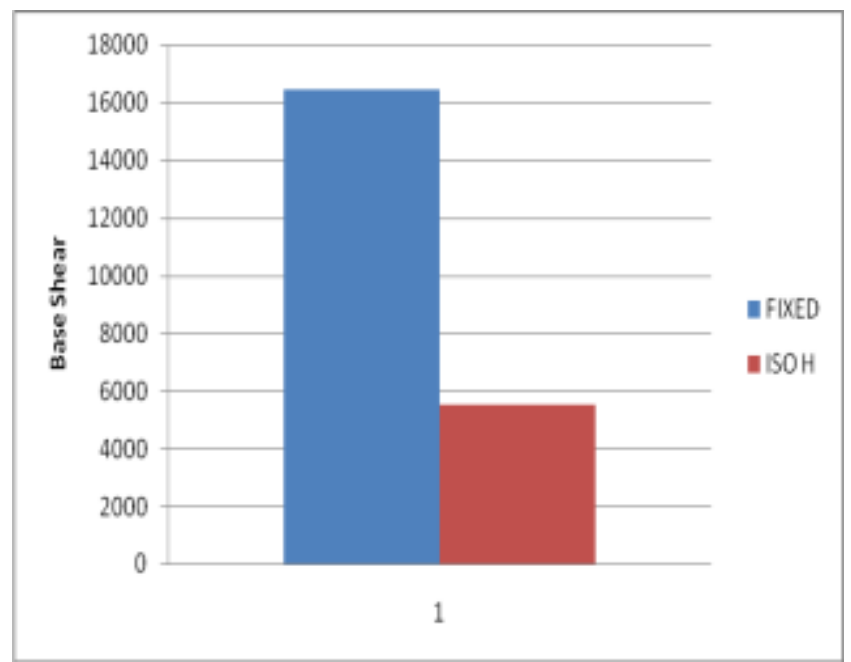

Fig 9: Variation of Base Shear (Zone V) 


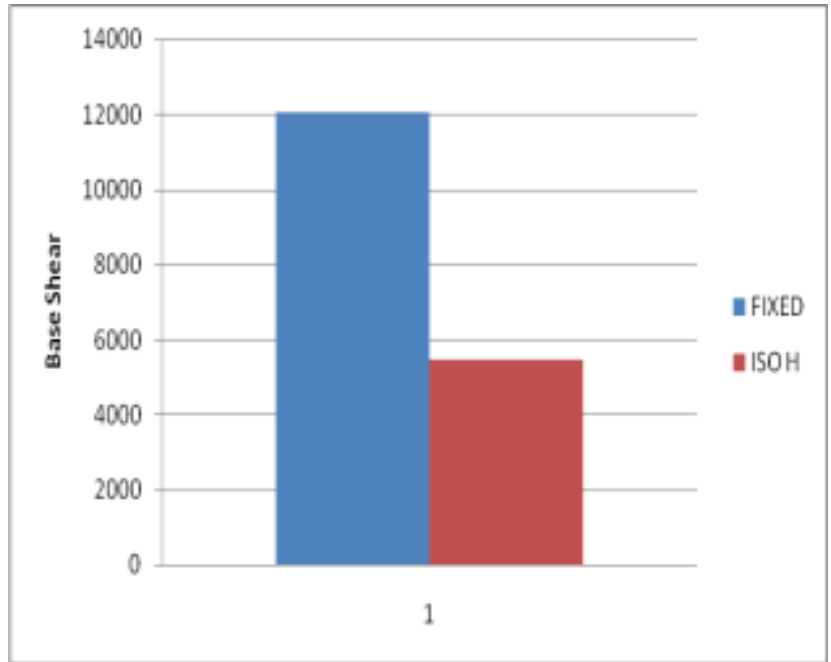

Fig 10: Variation of Base Shear (El-Centro)

The variation of the energy dissipation for fixed and isolated buildings under zone $\mathrm{V}$ and El-Centro earthquake inputs are plotted in fig 11 and fig 12 respectively.

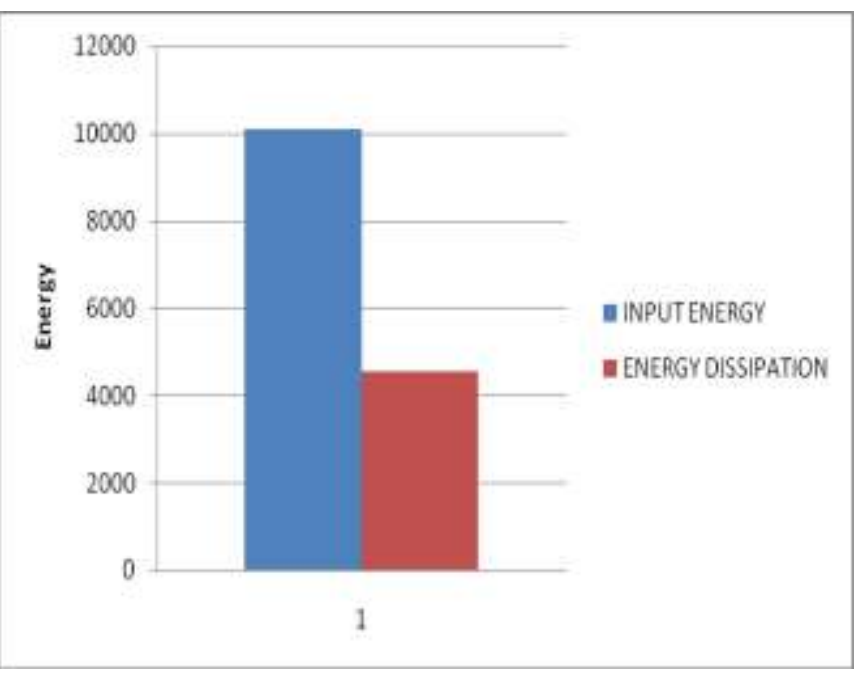

Fig 11: Variation of Energy Dissipation (Zone V)

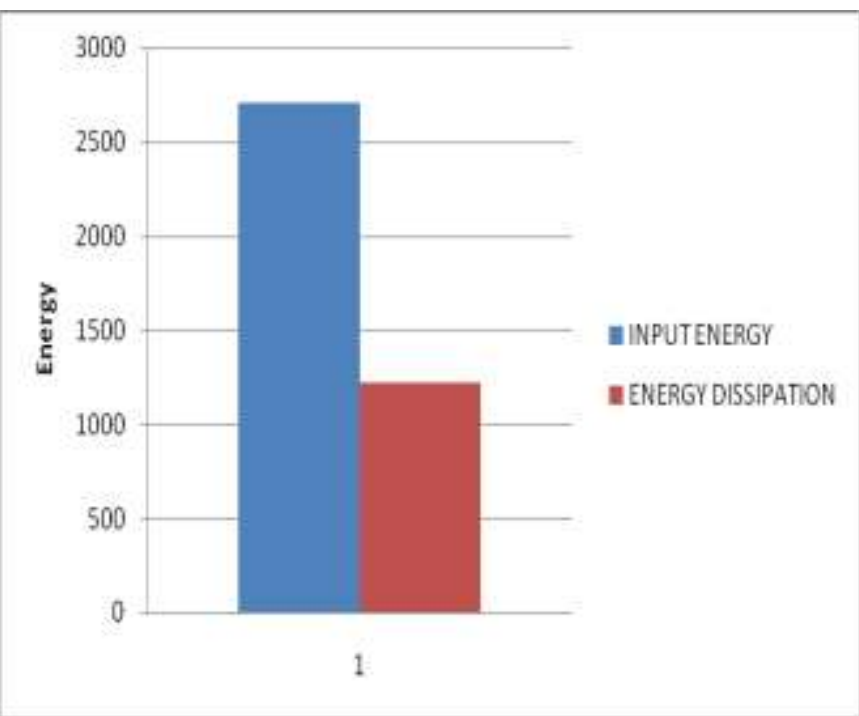

Fig 12: Variation of Energy Dissipation (El-Centro)
From the results, the effectiveness of base isolation is clear in terms of reducing the response of the structure under action of earthquake. There is a reduction in the inter-storey drift in case of base isolated building in comparison of fixed base building along with constant values of acceleration from top to bottom stories. Drastic reduction in the values of axial loads and base shear for both earthquake records was found. A significant reduction in energy dissipation is noted by introducing base isolators..

\section{CONCLUSION}

From the comparative study on the G+10 reinforced concrete structure, the following conclusions are drawn

- Due to increase in the fundamental period, the base isolated structure is removed out of the resonance range of earthquake

- Response reduction is significant in case of base isolated structure

- The forces induced in the superstructure are reduced significantly. Hence lighter sections can be used.

- The functionality of the structure can be ensured during and after the earthquake

- Thus the base isolation technique proves to be effective in zone $\mathrm{V}$ and El-Centro time history records

\section{REFERENCES}

[1] Arya AS (1994) Concepts and techniques for seismic base-isolation of structures, Earthquake Engineering, Tenth World Conference, ISBN 9054100605

[2] Jain SK, Thakkar SK (2004) Application of base isolation for flexible buildings, $13^{\text {th }}$ World Conference on Earthquake Engineering, Paper No 1924

[3] Salic RB, Garevski MA, Milutinovic ZV (2008) Response of lead-rubber bearing isolated structure, $14^{\text {th }}$ World Conference on Earthquake Engineering, Beijing, China

[4] Monfared H, Shirvani A, Nwaubani S (2013) An investigation into the seismic base isolation from practical perspective, International jornal of civil and structural engineering, Volume 3, No 3, 2013

[5] Kalantri SM, Naderpor H, Vaez SRH (2008), Investigation of base-isolator type selection on seismic behavior of structures including story drifts and plastic hinge formation, $14^{\text {th }}$ World Conference on Earthquake Engineering, Beijing, China

[6] Gani S, Gharad AM (2014), Comparative study and analysis of multi-storied base isolated building, imanager's journal on structural engineering, Vol 2, No 4

[7] Reddy AR, Ramesh V (2015), Seismic analysis of base isolated building in RC framed structures, International journal of civil and structural engineering research, Vol 3 , Issue 1, pp 170-176

[8] Kilar V, Koren D, (2008), Usage of simplified N2 method for analysis of base isolated structures, $14^{\text {th }}$ World Conference on Earthquake Engineering, Beijing, China 